\title{
The Design and Production of Fundamental Nursing MOOCs
}

\author{
Yan $L i^{1, a}$ \\ ${ }^{1}$ College of Nursing, Hubei University of Medicine, Shiyan, Hubei, China \\ aLainy24@126.com
}

Keywords: Fundamental Nursing; MOOCs; design; production.

\begin{abstract}
With the development of information technology, MOOCs as a new mode of open education have raised a hot wave of education reform in the global scope, and also provides an opportunity for the development of higher nursing education in China. This paper detailed expounds the process of design and production of the Fundamental Nursing MOOCs to provide references for other nursing educators to build their own MOOCs. Under the environment of higher education reform, higher nursing education professional should comply with the trend and seize the development opportunity to deepen the reform of teaching and cultivate a better nursing talents.
\end{abstract}

\section{Introduction}

Massively open online courses, MOOCs, has attracted attention and rapid development since this concept is raised in 2008[1], are center stage and seem to be trending on the higher education as the world[2]. Numerous MOOCs are offered in multiple areas in literature, art, mathematics, medicine and other fields, and provide rich high quality resources for the masses of MOOCs learners. MOOCs have the potential to massively challenge the traditional didactic and institution-bound learning[3]. It is about determining the best practices and improving the learning experience to not only provide knowledge, but also, promote the development of innovation and creativity[4].

MOOCs in the field of nursing education is in its infancy, and there is not report on the design and production of fundamental nursing MOOC. In this paper, the process of construction of fundamental nursing MOOC offered by our university will be expounded in detail. The aim of this paper is to provide the references for other nursing educators to build their own MOOCs.

\section{Current status of nursing MOOCs at home and abroad}

There are three powerful international platform of MOOCs: Coursera, Udacity and edX in which health and medical courses include. The number of MOOC is gradually increasing, but the development of MOOCs of higher nursing education is relatively lagging behind, and only a few universities, such as University of California San Francisco, Duke University and Alabama Birmingham, set up nursing MOOCs[5].

School online (http://www.xuetangx.com/), Good University Online (http://www.cnmooc.org /home/index.mooc), Chinese University MOOCs (http://www.icourse163.org/) are the three main platform of MOOCs in China. Five medical curriculum MOOCs have been offered in Chinese University MOOC, and six medical curriculum MOOCs and one nursing MOOCs have been opened in Good University Online. Some nursing MOOCs courses established by the college of nursing of Shanghai Jiaotong University, Central South University and Tianjin Medical University. Chinese medicine education MOOCs league, launched by more than 53 Chinese medical universities united by People's Medical Publishing House, will bring epoch-making significance in the development of medical education and open a new era of medical education in China.

As one of the members of the alliance, our university took charge of the construction of fundamental nursing MOOCs. The MOOCs have been put into used in March 2016, and can be available for free on the platform of Chinese medicine education MOOCs (http://www. pmphmooc.com/) for any MOOCs learners. 


\section{Traditional Teaching Characteristics of Basic Nursing}

Fundamentals of nursing is one of the earliest professional courses contacted by nursing students, and has a pivotal position in nursing education, and contains the basic theory, knowledge and skills of nursing. Nursing students are introduced to a challenging and rewarding profession, and are provided with a knowledge base to ground the development of caregiving skills and behaviors.

Traditional theory teaching of fundamental nursing has the following characteristics: teachers are a core of the classroom, students are accustomed to "were told", and the teaching method is relatively single for a long time. The traditional teaching process basically is divided into five steps, that is class introduction, knowledge review, new knowledge taught, knowledge to use, class summary. The cramming method of teaching have existed for a long time, which result in students lack of thinking and interaction in the learning and student-based teaching philosophy can't reflect. Instructor demonstrates and students exercises are the process in the traditional operation class of fundamental nursing. It is hard for students to grasp the procedure fully which cause poor practice ability of nursing students.

Promoting the comprehensive qualities of students and cultivating nursing students in line with international standards has always an important content of higher nursing education in China. It not only includes the internalization of the knowledge and skills, also reflects in the improving of the ability of humanistic, critical-thinking, autonomous-learning, communication skills of nursing students, so the traditional way of nursing education is difficult to meet the requirements of today's society. A new direction for the reform of nursing education provided by the MOOCs appeared.

\section{The design and production of fundamental nursing MOOC}

Course outline making. Compared with the the ordinary course contained 40 minutes of classroom teaching, fragmentation knowledge outline is one of significant characteristic of MOOCs formulated on the basis of characteristics of MOOCs learners and the full understanding of curriculum knowledge. Another marked feature is that MOOCs video consisted of short film about five to ten minutes which make MOOCs learners learn anytime and anywhere through scattered their fragment time. In order to better understand and grasp the content of MOOCs, learners can watch the video repeatedly and also communicate with teachers and other learners through online discussion. broken the content of course down into many individual knowledge on the basis of comprehensive understanding of curriculum knowledge is the foundation of making syllabus. MOOCs builders need mainly consider how to organize all of refining points as a whole.

Fundamental nursing MOOCs consisted of 18 chapters, about 32 hours long and 235 smallest knowledge points, incorporated in theory and practice video and still broadness knowledge. As an example, care for patients admitted and discharged from hospital in chapter 3 not only cover the content on textbook but also increase and update the knowledge points. The update knowledge is grading nursing care designed in accordance with new requirement issuing by the National Health and Family Planning commission of the People's Republic of China in 2013 after our MOOC team discussing, but it was described in fifth edition teaching material of fundamental nursing published by People's Medical Publishing House according to "general hospital grading nursing guidelines (trial)" issued in 2009. In parallel, in order to ensure the clear explain of the point, it is also increased the corresponding knowledge, such as self-care ability appraisal, the comparison of grading nursing 2009 edition with 2013 edition. In addition, two knowledge, follow-up after discharge and hierarchical medical, added into the MOOC video as extra-curricular knowledge.

Operation video in chapter 3 include Practice three procedure: bed-making, wheelchair transportation and flatcar transportation. After our MOOCs team discussion, making a post-operative bed and changing an occupied bed are selected to be shoot on behalf of bed-making. Meanwhile the film of flatcar transportation give a detailed introduction on transport patient by one person, two person, three person and four person separately. In the whole operation demonstration, the use of the human body mechanics principle are well reflected and give students a good example. 
To consolidate MOOCs learners' understanding of knowledge, a lot of exercise exist behind the corresponding video and every chapter to help MOOCs learners practice and master the knowledge.

Script design. The teaching content and the presentation way of knowledge has important influence on the learning enthusiasm of the MOOCs learners, can improve the effect of course and the completion rate of the MOOCs course. For the design of the script directly determines the final effect of video, teachers should complete the script and design their own teaching style according to the characteristics of the knowledge points.

Designing the content of the script is the most important work for teachers make MOOCs, and then teachers need determine the teaching and shoot ways in the process of script preparation. For example, location shooting, virtual scene shooting, powerpoint and teachers synchronous mode, full screen mode, scene demonstration mode, interview pattern and in-class recording mode can be selected by MOOC builders. We chose three modes in the theory films respectively are location shooting, virtual scene shooting and scene demonstration mode, operation films are all the mode of scene demonstration.

After the teaching style is determined, teachers can start to make the script included test material, pictures, two-dimensional or three-dimensional animation and other material. Script apply to teachers and also is the only reference for the late video editing staff when they produce video. So the script must be formulated in detail. How to let the script performance very clear? One way is tagging and indicating the arrangement manner of the content appeared in the video, another way is indicating the time and way of the images and animation. These methods can help video editors better understanding the script and is advantageous to the video post-processing.

Video shooting. A reasonable time arrangement is very important for smooth MOOC video shooting. Shooting in the normal teaching semester using no lesson time or in the winter and summer vacation to complete is all OK. Our MOOC video shoot in the summer vacation.

Theory of video shooting is simple, the time of shooting is mainly connected with the performance of teacher in front of lens. If teachers act natural and taught fluent at the camera, filming will progress quickly, vice versa, waste a lot of time due to require repeated remake. Pay attention to avoid such common problem as eyes without camera, rapid speech, slip of tongue, serious facial expressions, stiff body and other problems in the process of theoretical video shooting is necessary.

Operation video shooting more complicated than theory video. Teacher's location and the focus of the procedure in the process of operation demonstration are continuously changing, in order to guarantee the good effect of video, every change need a lot of time to adjust the lights and cameras, hence twenty minutes of video need to be taken about 6 hours of shooting. One operation procedure is an intact MOOCs video which is not simple rendering of operation process but need MOOCs builders through the special design and display form to help MOOCs learners understand the practical application of the operation on the basis of familiar with the operation procedure, at the same time through as much as video technology, such as slow motion, double lens display,etc., bring new experience to the learners and improve the learning enthusiasm and effect of students.

Changing the video shooting model can effectively relieve the MOOCs learners' visual fatigue. If teacher choose the location shooting mode, the selection and arrangement of a scene is an important issue that teacher must face. Lighting is one of the most important content in scene layout, and video shooting should avoid exposure ,shadows and other issues. The goof should be avoided in the part of content needed to re-shoot.

Modified and upload the video. All of these, Video editing, text rending, pictures and short video inserting, background music, operation video dubbing and video cations, etc., is responsible by the production company to complete. The initial video will appear in a variety of problems, teachers need make suggestions for revision about any unsatisfactory after watching the video over and over again. Any details can not be ignored because this is the last barrier to ensure the quality of video. MOOCs video really finished after at least 3 to 4 times modification. If you need animation, there is also need to communicate with production personnel about the content of the animation, and then modify repeatedly to ensure the animation effect reached the standard of teachers' expectations and 
requirements. Precise post-production is icing on the cake. In order to guarantee the unified effect of whole MOOCs video, the titles, trailer and captions of video should be consistent.

Video production has no fixed pattern, even if the same course, different points of the video display forms are completely different. On the basis of fully display the teaching content, MOOCs learners should be given a wonderful learning experience by increasing the interest, novelty and uniqueness of video design.

After the completion of the video modification, uploaded the MOOCs video to the internet platform according to the teaching progress and free open to the MOOCs learners. Fundamental Nursing MOOC, applied for the first planning courses of Chinese medicine education MOOCs league, have been put into used in March 2016 on MOOCs network platform（http://www.pmphmooc.com/) builded by People's Medical Publishing House.

\section{Conclusions}

It is a big challenge for teachers to design and product the MOOCs[6]. In the disign and production of MOOCs video, teachers need to have a clever idea and put a lot of time and energy on it. In addition to the students, the teacher is also a MOOCs beneficiaries. MOOCs are an inexpensive and effective way of bringing university to anyone who interesting in studying[7]. Under the environment of higher education reform, higher nursing education professional how to comply with the trend, seize the development opportunity, deepening the reform of teaching, cultivate a better nursing talents, is the issues of shared concern for the general nursing educators to discuss.

\section{Acknowledgement}

Supported by the Research Fund Program of 2014 provincial teaching research in colleges and universities of Hubei Province projects, Project number:2014334; The teaching research project of Hubei University of Medicine, Project Number: 2014012.

\section{References}

[1] Skinba D. J., Disruption in higher education: massively open online courses(MOOCs), Nurs. Educ. Perspect. 33(2012) 416-417.

[2] Skiba, D.J., On the Horizon: The Year of the MOOCs, Educ. Perspect. 34(2013), 136--137.

[3] Bellack, J.P., MOOCs: the future is here, J. Nurs. Educ. 52(2013), 3-4.

[4] Skiba, D.J., MOOCs and the Future of Nursing. Nurs. Educ. Perspect. 34(2013), 202--204.

[5] Desilets, L. D., No longer a passing fad. J. Contin. Educ. Nurs. 44(2013):149-150.

[6] Li Xiaodong, Challenges of MOOC to University Teachers' Quqlifications and Countermeasures. Journal of Nanjing university of Science and Technology. 27(2014), 89--92.

[7] Sarabia-Cobo, C. M., Torres-Manrique, B., Ortego-Mate, M. C., Continuing education in patient safety massive open online courses as a new training tool. J. Contin. Educ. Nurs. 46(2015), 446-447. 